\title{
KARAKTERISTIK PERIKANAN TANGKAP DI KEPULAUAN KANGEAN, KABUPATEN SUMENEP, MADURA \author{
Sumenep, Regency Madura
} \\ Characteristics of Capture Fisheries In the Kangean Islands of
}

\author{
*Suci Asrina Ikhsan dan Muhammad Nur Arkham \\ Politeknik Kelautan dan Perikanan Dumai \\ JI. Wan Amir No. 1, Kel. Pangkalan Sesai, Kota Dumai, Riau, Indonesia \\ Diterima tanggal: 22 Januari 2020; Diterima setelah perbaikan: 24 April 2020; \\ Disetujui terbit: 25 Juni 2020
}

\begin{abstract}
ABSTRAK
Perikanan skala kecil sangat penting di negara berkembang, dimana ketergantungan pada sumber daya pesisir sangat tinggi dan dapat memberikan kontribusi terhadap ketahanan pangan dan peningkatan pendapatan. Permasalahan yang dihadapi saat ini adalah adanya kebutuhan pangan yang sangat penting namun belum tereskplorasinya perikanan tangkap untuk daerah ini. Penelitian ini bertujuan untuk menganalisis karakteristik dan pemanfaatan sumber daya perikanan skala kecil di Kepulauan Kangean. Penelitian ini berlokasi di Kepulauan Kangean, tepatnya di Kecamatan Raas. Pengumpulan data dilakukan melalui wawancara, observasi, dan pengarsipan data pendukung. Analisis deskriptif kualitatif digunakan dalam penelitian ini. Hasil penelitian menyebutkan bahwa karakteristik perikanan tangkap yang ada di pulau-pulau di Kecamatan Raas adalah nelayan skala kecil. Nelayan skala kecil yang ada di lokasi penelitian melakukan aktivitas penangkapan hanya di sekitar pantai dan tidak jauh dari pantai. Alat tangkap yang digunakan oleh nelayan kecil di lokasi penelitian adalah pancing tonda, pancing gurita, gillnet, pancing ulur, dan bubu lipat. Armada penangkapan yang digunakan adalah kapal tanpa motor (sampan) sebanyak $62 \%$ dan kapal motor dengan kapasitas < 5 GT sebanyak $30 \%$. Musim penangkapan nelayan kecil ini sangat dipengaruhi oleh musim dan kondisi ekosistem perairan disekitar.
\end{abstract}

Kata Kunci: nelayan skala kecil; aktivitas nelayan; pulau-pulau kecil; Kepulauan Kangean

\section{ABSTRACT}

Small-scale fisheries play an important role in developing countries where they highly depend on coastal resources. Moreover, small-scale fisheries make a significant contribution to food security and income enhancement. The problem occurs when the capture fisheries have not been explored in this area while there are a significant needs of food. The purpose of this research was to analyze the characteristics and utilization of small-scale fisheries resources in the Kangean Islands. The location of the research was in District of Raas, Kangean Islands. Data were collected from interviews, observation, and supporting data archives. The study used qualitative descriptive analysis. The results of this study identified that the characteristics of capture fisheries in the District of Raas, Kangean Islands, are small-scale fishers. The fishing activities of those small-scale fishers are conducted around the beach. They use trolling, octopus fishing rod, gillnet, fishing line, and folding traps. The fishing fleet used by the small-scale fishers are mostly non-motorized boats (canoe) as much as $62 \%$ and motorboats with capacities <5GT as much as $30 \%$. The fishing season of these small-scale fishers is highly influenced by the season and condition of the surrounding aquatic ecosystem.

Keywords: small-scale fishers; fishing activities; small islands; Kangean Islands

\section{PENDAHULUAN}

Keberadaan usaha nelayan dan masyarakat pesisir di Indonesia masih didominasi oleh usaha perikanan skala kecil yaitu sekitar $85 \%$, dan hanya sekitar $15 \%$ di lakukan oleh usaha perikanan skala yang lebih besar (Nababan, Yesi, \& Maman, 2008). Menurut McConney \&
Charles (2008), menyebutkan bahwa operasi penangkapan nelayan skala kecil yaitu berada dekat dengan pantai dan menggunakan armada penangkap ikan yang relatif kecil. Alat penangkap ikan yang digunakan oleh nelayan skala kecil adalah alat penangkap ikan tradisional, seperti jaring kecil, perangkap/bubu, pancing, jubi/tombak, dan metode-metode pengumpul dengan tangan 
dan beberapa yang telah dimekanisasi (Berkes et al., 2008). Seperti yang digambarkan dari hasil penelitian Fathanah (2014) menyebutkan bahwa aktivitas perikanan skala kecil yang ada di pesisir selatan Jawa Timur tersebar di sepanjang pantai dengan variasi alat tangkap seperti perangkap (trap), jaring insang, pancing, pukat tarik, dan jaring lingkar yang dipengaruhi oleh musim dan kondisi lingkungan. Upaya penangkapan ikan yang dilakukan oleh nelayan kecil tersebut dipengaruhi oleh musim, ikan target penangkapan dan daerah penangkapannya.

Perikanan skala kecil (small-scale fisheries) sangat penting di negara berkembang, di mana ketergantungan pada sumber daya pesisir sangat tinggi dan dapat memberikan kontribusi terhadap ketahanan pangan dan peningkatan pendapatan. Namun demikian, perhatian pemerintah terhadap pengelolaan perikanan tangkap skala kecil menjadi lebih rendah dibandingkan dengan perhatiannya terhadap industri penangkapan ikan. Pengelolaan perikanan skala kecil pengerjaannya juga lebih rumit, sebagai sumber penghasilan, biasanya tidak terdaftar dan tidak diakui oleh lembaga pengelolaan (Arkham, Adrianto, \& Wardiatno, 2015b). Pembangunan perikanan tangkap pada hakekatnya ditujukan untuk meningkatkan kesejahteraan masyarakat, khususnya bagi para nelayan dan sekaligus untuk menjaga kelestarian sumberdaya ikan serta lingkungannya (Imam, 2012). Pengelolaan perikanan skala kecil sangat penting supaya pemnfaatannya tidak melebihi daya dukung sumberdaya perikanan di pesisir dan pantai. Pengelolaan sumberdaya perikanan merupakan sebuah proses yang harus dilaksanakan secara terintegrasi. Aktivitasnya meliputi pengumpulan informasi dan data, analisis data, perencanaan, konsultasi, pembuatan keputusan, alokasi sumberdaya, implementasi dan penegakan hukum dari peraturan perundangundangan di bidang perikanan (Carles, Wiyono, Wisudo, \& Soeboer, 2014). Aktivitas dari perikanan kecil yang ada di Indonesia sangat identik dengan pulau-pulau kecil yang ada di Indonesia. Kepulauan Kangean sebagai salah satu pulau kecil yang ada di Provinsi Jawa Timur sebagian besar masyarakat pesisirnya bekerja sebagai nelayan kecil dengan armada penangkapan ikan < 5 GT (BPS Kabupaten Sumenep, 2019).

Kepulauan Kangean merupakan gugusan pulau yang terletak di sebelah ujung timur Pulau Madura, Laut Jawa. Kepulauan ini terdiri dari sedikitnya 60 pulau, dengan luas wilayah
$487 \mathrm{~km}^{2}$. Pulau-pulau terbesar adalah Pulau Kangean $\left(188 \mathrm{~km}^{2}\right)$, Pulau Paliat dan Pulau Sapanjang. Kepulauan Kangean secara administrasi wilayah masih masuk dalam Kabupaten Sumenep, Pulau Madura, Provinsi Jawa Timur. Kecamatan Raas merupakan kecamatan di Kepulauan Kangean dengan masing-masing penduduk sebnyak 35.017 jiwa (BPS Kabupaten Sumenep, 2019). Sebagian besar masyarakat di Kepulauan Kangean mempunyai mata pencaharian sebagai nelayan. $\mathrm{Hal}$ ini ditunjang dengan keberadaan ekosistem pesisir dan sumberdaya perikanannya. Informasi mengenai karakteristik, pemanfaatan, dinamika dan aktivitas perikanan kecil yang dilakukan di Kepulauan Kangean menjadi sangat penting untuk dijadikan sebagai dasar dalam menentukan kebijakan dan peraturan di bidang perikanan. Tujuan dari dilakukannya penelitian ini adalah untuk menganalisis karakteristik dalam pemanfaatan sumberdaya perikanan kecil di Kepulauan Kangean.

Lokasi dalam penelitian ini adalah di Kepulauan Kangean tepatnya di Kecamatan Raas. Pertimbangan pemilihan lokasi penelitian dikarenakan Kecamatan Raas merupakan salah satu Kecamatan Pesisir yang masuk dalam wilayah Kepulauan Kangean dengan jumlah nelayan pada kategori nelayan kecil (armada penangkapan $<10 G$ ) sebesar 10\% (230 unit) dan merupakan urutan ketiga terbanyak di Kabupaten Sumenep (BPS Kabupaten Sumenep, 2019). Kepulauan Kangean ini tepatnya berada di Pulau Madura, Provinsi Jawa Timur. Berdasarkan penelitian dari Romadhon (2014), Pulau Gili Labak sebagai salah satu pulau kecil yang berada di Kabupaten Sumenep, sebagai salah satu kawasan yang memiliki perikanan skala kecil memerlukan suatu strategi pengelolaan perikanan melalui penetapan kawasan konservasi. Hal ini dapat dilakukan melalui penilaian kondisi perikanan skala kecil dan perumusan strategi pengelolaan perikanan berkelanjutan sebagai bentuk implementasi. Waktu pelaksanaan penelitian sendiri dilakukan selama 2 minggu dimulai dari tanggal $7-21$ Desember 2017. Lokasi penelitian dapat dilihat pada Gambar 1.

Penelitian ini menggunakan pendekatan snowball dengan metode kualitatif. Teknik sampling snowball sebagai salah satu teknik sampling yang dapat diandalkan untuk mendapatkan data dari responden guna menjawab permasalahan penelitian lapangan yang bersifat 




Gambar 1. Peta Lokasi Penelitian.

Figure 1. Location Map Research.

Sumber : www.google.co.id/maps/Source : www.google.co.id/maps

khusus (Nurdiani, 2014). Metode kualitatif menekankan analisis dari proses berpikir secara induktif yang berkaitan dengan dinamika hubungan antar fenomena yang diamati, dan senantiasa menggunakan logika ilmiah. Penelitian kualitatif dapat mengeksplorasi sikap, prilaku dan pengalaman responden melalui metode interview agar peneliti dapat dengan mudah mengategorikan secara rinci permasalahan. Jumlah responden yang dalam pada penelitian sebanyak 30 orang. Penelitian kualitatif berusaha mengkonstruksi realitas dan memahami makna (Sinabutar, 2015).

Data diperoleh secara langsung dari sumber data utama publikasi, laporan statistik perikanan Kab Sumenep, data badan pusat statistik (BPS), dan laporan-laporan lain mengenai kondisi perikanan tangkap di lokasi studi yang berkaitan dengan topik penelitian. Jenis data, cara pengambilan dan sumber data yang digunakan pada penelitian ini dapat dilihat pada Tabel 1 .

\section{Analisis Data}

\section{A. Analisis Daerah Penangkapan Ikan}

Analisis peta daerah penangkapan ikan nelayan dilakukan dengan menggunakan perangkat lunak sistem informasi geografis (SIG) dengan softwere ArcGIS. Perangkat ini digunakan untuk merubah data peta dan memasukkan titik koordinat dari tangkapan nelayan menjadi data polygon, line, dan point (data raster ke vektor). Selanjutnya dari hasil analisis spasial akan didapatkan titik-titik penangkapan dari nelayan lokal dalam memanfaatkan ekosistem lamun dari data titik koordinat yang didapat dari GPS. Setelah didapatkan hasil overlay ditarik garis dari setiap titik yang didapat pada peta untuk hasil

Tabel 1. Jenis, Cara Pengambilan dan Sumber Data yang Digunakan Pada Penelitian. Table 1. Type and Source of Data Collected in This Research.

\begin{tabular}{|c|c|c|c|}
\hline No & Jenis Data/Data Type & $\begin{array}{l}\text { Cara Pengambilan Data/ } \\
\text { Method of Data Sampling }\end{array}$ & $\begin{array}{l}\text { Sumber Datal } \\
\text { Data Source }\end{array}$ \\
\hline \multirow[t]{4}{*}{1} & Data Primer/Primer Data: & & \\
\hline & $\begin{array}{l}\text { - Daerah Penangkapan Ikan/ } \\
\text { Fishing Ground }\end{array}$ & $\begin{array}{l}\text { Interview dan Partisipatif/ } \\
\text { Interview and Participatory }\end{array}$ & Kelompok Nelayan/Fisher Group \\
\hline & $\begin{array}{l}\text { - Musim Penangkapan Ikan/ } \\
\text { Fishing Season }\end{array}$ & Wawancara/Interview & Kelompok Nelayan/Fisher Group \\
\hline & $\begin{array}{l}\text { - Karakteristik Nelayan/Fisher } \\
\text { Characteristic }\end{array}$ & Wawancara/Interview & Kelompok Nelayan/Fisher Group \\
\hline \multirow[t]{3}{*}{2} & Data Sekunder/Data Seconds: & & \\
\hline & - Jumlah Nelayan/Fisher Total & $\begin{array}{l}\text { Partisipatif/Interview and } \\
\text { Participatory }\end{array}$ & $\begin{array}{l}\text { Dinas Perikanan Kabupaten } \\
\text { Sumenep dan BPS Kabupaten }\end{array}$ \\
\hline & $\begin{array}{l}\text { - Jumlah Armada Penangkapan } \\
\text { Ikan/Total Capture Fleet }\end{array}$ & $\begin{array}{l}\text { Partisipatif/Interview and } \\
\text { Participatory }\end{array}$ & $\begin{array}{l}\text { Sumenep/Sumenep Regency } \\
\text { Fisheries Office and Sumenep } \\
\text { Regency BPS }\end{array}$ \\
\hline
\end{tabular}


sebaran hasil tangkapan. Kemudian peta jaringan pemasaran dan dinamika perikanan skala kecil dijelaskan secara deskriptif dari hasil peta lokasi penangkapan digunakan untuk menggambarkan spasial dinamika dan pemasaran hasil tangkapan nelayan lokal dengan jaringan garis (line) yang menghubungkan keterkaitan antara satu dengan yang lain (Arkham, Adrianto, \& Wardiatno, 2015a).

\section{B. Analisis Karakteristik Nelayan dan Musim Penangkapan}

Analisis karakteristik nelayan dan musim penangkapan ini menggunakan analisis deskriptif kualitatif. Analisis deskriptif kualitatif adalah analisis penjelasan untuk data-data yang bersifat kualitatif. Proses analisis data dalam penelitian kualitatif antara lain pengumpulan data mentah, transkrip data, reduksi data, interpretasi data, dan penarikan kesimpulan. Analisis data dengan metode Creswell (2010), ini menyebutkan bahwa intepretasi data dari hasil studi kasus, fenomenologi, naratif, partisipatori dan grounded theory dari karakteristik kelompok nelayan kecil yang ada di lokasi studi.

\section{KARAKTERISTIK PERIKANAN}

\section{A. Jumlah Nelayan}

Jumlah nelayan Kecamatan Raas pada tahun 2012 sampai Tahun 2014 berdasarkan data BPS Kabupaten Sumenep tidak mengalami perubahan yaitu 2.638 orang. hasil pendataan yang dilakukan oleh Dinas Perikanan Kabupaten
Sumenep pada tahun 2016/2017 diketahui jumlah penduduk yang bekerja sebagai nelayan di Kecamatan Raas sebanyak 4.638 orang. rincian data selengkapnya mengenai jumlah nelayan menurut desa di Kecamatan Raas dapat dilihat pada Tabel 2.

Berdasarkan data pada Tabel 2 menunjukkan bahwa masyarakat di Kecamatan Raas, Kepulauan Kangean yang berprofesi sebagai nelayan sebanyak $12,42 \%$ dari jumlah total penduduk yang ada di Kecamatan Raas. Nelayan yang ada di Kecamatan Raas ini sebagian besar adalah nelayan kecil yang melakukan penangkapan hanya disekitar pantai dan tidak jauh dari pantai. Menurut McConney \& Charles (2008), menyebutkan bahwa nelayan skala kecil beroperasi dekat dengan pantai dan menggunakan kapal penangkap ikan yang relatif kecil dan milik sendiri. Berbeda dengan nelayan yang ada di Desa Tonduk, berdasarkan hasil survey dan wawancara menyebutkan bahwa nelayan tersebut sebagian besar adalah nelayan andon yang melakukan penangkapan sampai dengan ke perairan perbatasan Australia untuk mencari teripang. Nelayan yang ada di Desa Tonduk tersebut melakukan penangkapan selama 3 bulan, sehingga sebagian besar penduduk yang ada di desa tersebut perempuan. Kondisi pada desa tersebut yang sebagian besar kepala keluarganya adalah nelayan andon yang mencari teripang, sehingga Desa Tonduk tersebut sering disebut dengan Pulau Putri. Berikut ini adalah beberapa aktivitas nelayan yang telah dilakukan di wilayah studi berdasarkan dari hasil wawancara dan studi literatur tersaji pada Tabel 3.

Tabel 2. Jumlah Nelayan Menurut Desa di Kecamatan Raas Tahun 2016/2017. Table 2. Total of Fishers By Village in The Raas Sub Regency, 2016/2017.

\begin{tabular}{clccc}
\hline No & \multicolumn{1}{c}{ Desa/ Village } & $\begin{array}{c}\text { Jumlah Nelayan } \\
\text { (orang)/ Fisher } \\
\text { Total (people) }\end{array}$ & $\begin{array}{c}\text { Jumlah Penduduk } \\
\text { (orang)/ Population } \\
\text { (people) }\end{array}$ & $\begin{array}{c}\text { Persentase Jumlah } \\
\text { Nelayan (\%)/ Percentage } \\
\text { of Fisher (\%) }\end{array}$ \\
\hline 1 & Ketupat/Ketupat Village & 695 & 5,875 & $11.83 \%$ \\
2 & Jungkat/Jungkat Village & 52 & 2,428 & $2.14 \%$ \\
3 & Karopah/Karopah Village & 285 & 4,958 & $5.75 \%$ \\
4 & Karang Nagka/Karang Nagka Village & 423 & 4,296 & $9.85 \%$ \\
5 & Alas Malang/Alas Malang Village & 210 & 2,765 & $7.59 \%$ \\
6 & Poteran/Poteran Village & 250 & 2,680 & $9.33 \%$ \\
7 & Brakas/Brakas Village & 1,028 & 5,546 & $18.54 \%$ \\
8 & Tonduk/Tonduk Village & 787 & 4,967 & $15.84 \%$ \\
9 & Guwa-Guwa & 908 & 3,839 & $23.65 \%$ \\
\multicolumn{7}{c}{ Island } & 690 & & \\
\hline
\end{tabular}

Sumber: Dinas Perikanan Kabupaten Sumenep, 2018/Remaks: Dinas Perikanan Kabupaten Sumenep, 2018 
Tabel 3. Deskripsi Aktivitas Nelayan di Beberapa Lokasi Studi. Table 3. Description of Fishers's Activities in Several Study Locations.

\begin{tabular}{|c|c|c|}
\hline No & Lokasi/Location & Deskripsi Aktivitas/Activity Description \\
\hline 1 & $\begin{array}{l}\text { Pulau Komirian/ } \\
\text { Komirian Island }\end{array}$ & $\begin{array}{l}\text { Mata pencaharian penduduk Pulau Komirian adalah nelayan, perkebunan kelapa, } \\
\text { TKI. Penjualan kelapa ke Panarukan dan Raas dengan frekuensi seminggu sekali. } \\
\text { Alat tangkap yang dioperasikan nelayan sebagaian besar adalah pancing ulur (hand } \\
\text { line), jaring dan pancing rawai dengan mata pancing no } 8 \text {. Operasi penangkapan ikan } \\
\text { umumnya dilakukan } 1 \text { orang nelayan. Jenis ikan yang tertangkap adalah ikan baronang, } \\
\text { ikan ketambah, ikan kakap merah, ikan kerapu. Biaya operasional sekitar } 150.000 \text { untuk } \\
\text { pembelian solar } 5-10 \text { Iter (@Rp9.000), umpan } 2-5 \mathrm{~kg} \text { (@Rp10.000). Produksi melimpah } \\
\text { ketika musim barat. Orientrasi ekonomi ke Arjasa (Kangean) setiap hari Senin dan Jumat } \\
\text { dengan biaya Rp50.000 (PP) lama perjalanan } 2 \text { jam / The livelihoods of residents of } \\
\text { Komirian Island are Fishers, coconut plantations, TKI. Coconut sales to Panarukan and } \\
\text { Raas with frequency once a week. Most of the fishing gear operated by Fishers is hand } \\
\text { line, nets, and longline with no. } 8 \text { fishing operations. Generally, one fishing operation } \\
\text { is carried out. The types of fish caught are baronang fish, sprouted fish, red snapper, } \\
\text { grouper fish. Operating costs around 150,000 for the purchase of } 5-10 \text { liter diesel fuel } \\
\text { (@ IDR9,000), 2-5 kg of feed (@ IDR10,000). Production is abundant during the west } \\
\text { season. Economic concentration to Arjasa (Kangean) every Monday and Friday for at } \\
\text { IDR50,000 (PP), a 2-hour long trip. }\end{array}$ \\
\hline
\end{tabular}

2 Desa Guwa-Guwa/ Masyarakat yang tinggal di Desa Guwa-Guwa memiliki ketergantungan dari hasil laut. Guwa-Guwa Village Mata pencaharian utama masyarakat di Desa Guwa-Guwa yaitu nelayan. Jenis alat tangkap yang digunakan oleh masyarakat di Desa Guwa-Guwa yaitu pancing ulur, pancing tonda, gillnet, tombak garfu. Lokasi penangkapan ikan berada di sekitar pulau. Setiap 3 hari terakhir bulan qomariyah tepatnya tanggal 27, 28, 29 terdapat banyak ikan maningsing (Baronang) yang bertelur. Masyarakat di sekitar pulau Guwa-Guwa mengambil ikan tersebut dengan cara dijaring bahkan cukup diserok / People living in the village of Guwa-Guwa have a dependency on marine products. The main livelihoods of the people in Guwa-Guwa Village are Fishers. The types of fishing gear used by the community in Guwa-Guwa Village are stretching fishing rods, trolling rods, gillnet, garfu spear. Fishing locations are around the island. Every last 3 days of the qomariyah month on the 27th, 28th, 29th there is a lot of Maninging fish (Baronang) laying eggs. Communities around the island of Guwa-Guwa take the fish by being netted and even being scooped out.

3 Desa Tonduk/ Tonduk Village

4

Desa Brakas/ Brakas Village
Aktivitas penangkapan yang dilakukan oleh penduduk di Desa Tonduk banyak yang melakukan penangkapan teripang. Daerah operasi penangkapan teripang berada diluar wilayah Madura, bahkan hingga ke daerah Pulau Bacan. Sekitar 30\% penduduknya melakukan penangkapan teripang hingga ke pulau bacan. Operasi penangkapan teripang dapat berlangsung selama 2-6 bulan. Bahkan sebagian penduduknya ada yang menetap di wilayah Pulau Bacan / Catching activities carried out by residents in the village of Tonduk many do catch sea cucumbers. The sea cucumber operation area is outside the Madura area, even to the Bacan Island area. About 30\% of the population makes sea cucumbers catch up to Bacan island. Sea cucumber capture operations can last for 2-6 months. Some of the residents even settled in the Bacan Island area.

Desa Brakas merupakan wilayah ibukota Kecamatan Raas, sehingga desa ini merupakan pusat aktivitas perdagangan. Kegiatan pengangkutan/pengiriman ikan hasil tangkapan nelayan setempat dikirim melalui desa ini. Sekitar $30 \%$ penduduk di desa brakas banyak yang keluar daerah terutama ke Bali. Sebagian penduduk di Desa Brakas juga berprofesi sebagai nelayan. Jenis alat tangkap yang digunakan yaitu pancing tonda, pancing ulur dan jaring / Brakas Village is the capital region of Raas District, so this village is a center of trading activity. Transporting / shipping activities of fish caught by local Fishers are sent through this village. Approximately $30 \%$ of the population in the village of Brakas many who exit the area, especially to Bali. Some residents in the village of Brakas also work as Fishers. Types of fishing gear used are trolling, stretching and netting.

\section{B. Armada Penangkapan Ikan}

Jenis armada penangkapan ikan yang sering beroperasi di perairan Kecamatan Raas meliputi perahu tanpa motor, perahu motor tempel, dan kapal motor. Jenis armada penangkapan ikan yang dominan digunakan nelayan di wilayah studi adalah perahu tanpa motor yaitu sebanyak $62,5 \%$. Data selengkapnya mengenai jumlah armada penangkapan ikan menurut ukuran kapal yang digunakan oleh nelayan di lokasi studi dapat dilihat pada Tabel 4. 
Tabel 4. Jumlah Armada Penangkapan Ikan menurut Desa di Kecamatan Raas Tahun 2015 (satuan unit)

Table 4. Total of Fishing Fleets by Village in Raas Sub Regency, 2015 (unit).

\begin{tabular}{|c|c|c|c|c|c|}
\hline No & Desa/ Village & $\begin{array}{c}\text { Perahu Tanpa } \\
\text { Motor/ Motoris } \\
\text { Boat }\end{array}$ & $\begin{array}{c}\text { Perahu Motor } \\
\text { Tempel/ Outboard } \\
\text { Motorboats }\end{array}$ & $\begin{array}{l}\text { Kapal Motorl } \\
\text { Motor Boat }\end{array}$ & $\begin{array}{c}\text { Jumlah/ } \\
\text { Total }\end{array}$ \\
\hline 1 & Ketupat/Ketupat Village & 84 & 31 & 13 & 128 \\
\hline 2 & Jungkat/Jungkat Village & 24 & 9 & 3 & 36 \\
\hline 3 & Karopah/Karopah Village & 57 & 33 & 8 & 98 \\
\hline 4 & Karangnagka/Karangnagka Village & 38 & 20 & - & 58 \\
\hline 5 & Alasmalang/Alasmalang Village & 39 & 14 & 4 & 57 \\
\hline 6 & Poteran/Poteran Village & 60 & 21 & - & 81 \\
\hline 7 & Brakas/Brakas Village & 180 & 80 & 27 & 287 \\
\hline 8 & Tonduk/Tonduk Village & 236 & 134 & 30 & 400 \\
\hline \multirow[t]{2}{*}{9} & Guwa Guwa/Guwa Guwa Village & 122 & 69 & 8 & 199 \\
\hline & Jumlah/ Total & 840 & 411 & 93 & 1,344 \\
\hline
\end{tabular}

Sumber: Desa-Desa di Kecamatan Raas dalam [BPS] Kabupaten Sumenep, 2016/

Source: Desa-Desa di Kecamatan Raas dalam [BPS] Kabupaten Sumenep, 2016

Untuk lebih jelasnya mengenai gambaran armada penangkapan ikan yang berada di Kecamatan Raas dapat dilihat pada Gambar 2.

Berdasarkan hasil penelitian menyebutkan bahwa armada penangkapan yang digunakan oleh nelayan di lokasi studi adalah kapal motor < 30GT. Sebagian besar nelaya menggunakan sampan atau perahu tanpa motor dengan daerah penangkapan hanya disekitar pantai. Beberapa kapal motor yang ada di Desa Tonduk adalah kapal nelayan yang digunakan untuk mencari teripang sampai dengan perbatasan perairan Australia, dimana jumlah nelayan yang ada dikapal kurang lebih sebanyak 6-8 orang. Sedangkan untuk kapal kecil sebanyak 1-2 orang saja yang melakukan penangkapa disekitar pantai. Menurut Undang-Undang Nomor 45 Tahun 2009 tentang Perikanan, pasal 1 angka 11 lebih spesifik menyebutkan bahwa nelayan kecil adalah orang yang mata pencahariannya melakukan penangkapan ikan untuk memenuhi kebutuhan hidup sehari-hari dengan menggunakan kapal perikanan berukuran paling besar adalah 5 gross tonnage (GT).

\section{Alat Penangkap Ikan dan Pola Kepemilikannya}

Jenis alat penangkapan ikan yang digunakan nelayan di Kecamatan Raas meliputi jala, gillnet, bubu, pancing ulur dan pancing tonda. Masingmasing alat tangkap memiliki fishing ground dan ikan target masing-masing. Akan tetapi terdapat pula beberapa alat tangkap yang memiliki ikan terget dan fishing ground yang sama. Berdasarkan pola kepemilikan alat tangkap menyebutkan bahwa bahwa kepemilikan alat tangkap nelayan, sangat tergantung dari modal usaha yang mereka miliki. Bagi nelayan yang memiliki modal kecil, mereka hanya mengoperasikan jaring (gillnet) dan pancing ulur secara bergantian sesuai dengan musim penangkapan ikan target dari masing-masing alat

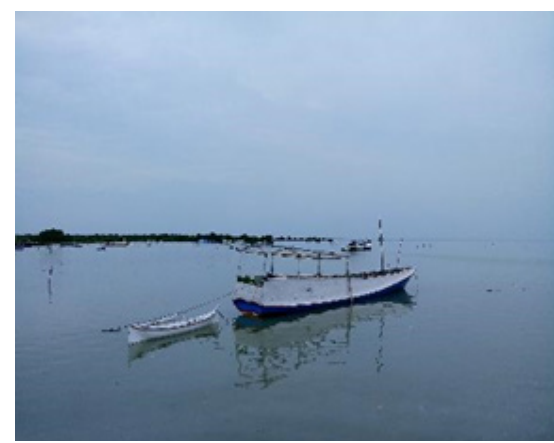

(a)

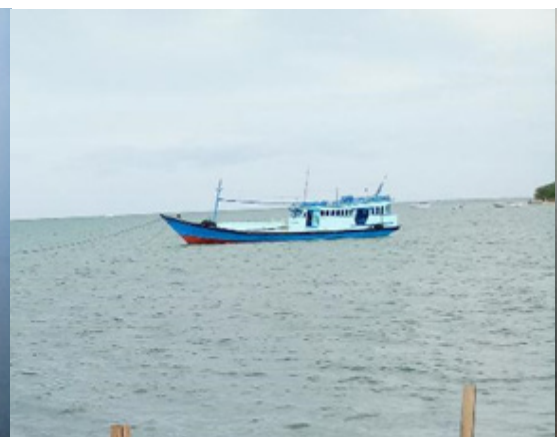

(b)

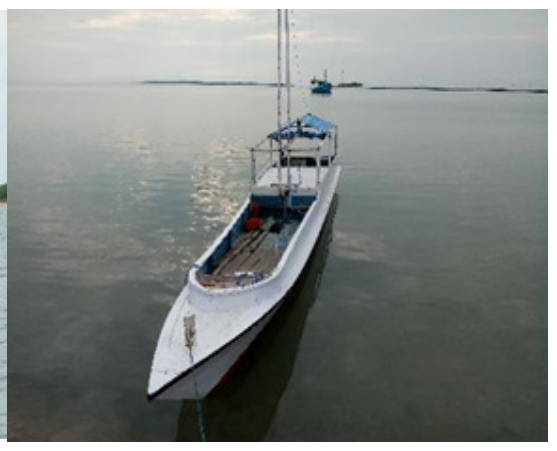

(c)

Gambar 2. Armada Penangkapan Ikan di Lokasi Studi (a) Desa Guwa Guwa (b) Desa Tonduk (c) Desa Brakas. Figure 2. Fishing Fleet at Study Sites (a) Guwa Guwa Village (b) Tonduk Village (c) Brakas Village. 
tangkap. Sementara nelayan yang lebih mampu akan mengkombinasikan gillnet, bubu dengan pancing ulur, sedangkan untuk alat tangkap pancing tonda hanya dimiliki oleh beberapa nelayan saja (tunggal). Semakin kuat modal usaha nelayan, mereka akan melengkapi alat tangkapnya selengkap mungkin. Gambaran mengenai jenis alat penangkap ikan yang digunakan oleh nelayan di lokasi studi dapat dilihat pada Gambar 3.

Menurut McConney \& Charles (2008), menyebutkan bahwa nelayan kecil melakukan operasi penangkapan dekat dengan pantai dan menggunakan kapal kecil dan milik sendiri. Alat penangkap ikan yang digunakan oleh nelayan kecil adalah alat penangkap ikan tradisional, diantaranya seperti jaring kecil, perangkap/bubu, pancing, jubi/tombak, dan metode pengumpul ikan dengan tangan dan beberapa yang telah dimodifikasi (Berkes et al., 2008). McGoodwin (2001), juga menyebutkan bahwa penggunaan teknologi penangkapan nelayan kecil merupakan hasil adaptasi terhadap perubahan daerah penangkapan dan jenis ikan targetnya. Kondisi ini menunjukkan bahwa nelayan kecil secara terus menerus melakukan upaya penangkapan ikan dengan berbagai cara yang dapat dilakukan, pada lokasi penangkapan yang terbatas dan jumlah yang banyak.

\section{Daerah Penangkapan Ikan}

Aktivitas penangkapan ikan oleh nelayan di Kecamatan Raas sebagian besar dilakukan secara one day fishing yaitu untuk setiap trip operasi penangkapan ikan dilakukan selama satu hari/ malam. Daerah penangkapan (fishing ground) alat penangkapan ikan jala dan jaring gillnet umumnya berada di sekitar pantai. aktivitas penangkapan pancing ulur dilakukan di sekitar lokasi karang. Wilayah operasi alat tangkap tersebut umumnya tidak jauh dari pantai berjarak antara 3-5 mil dari garis pantai dengan kedalaman perairan 3-10 meter. Lama pengoperasian dari alat tangkap ini adalah 3-5 jam dan dilakukan secara one day fishing. Hasil wawancara dengan nelayan di wilayah Kecamatan Raas diketahui bahwa nelayan di Desa Guwa Guwa, Desa Tonduk dan Desa Brakas dalam melakukan pengoperasian alat tangkap pancing tonda yaitu mengejar gerombolan ikan tongkol hingga berjarak jauh dari pantai (lebih dari $5 \mathrm{mil}$ ). Lamanya waktu perjalanan dalam mengejar gerombolan ikan tongkol tersebut selama 1,5 jam dari Desa Guwa Guwa atau 2 jam dari Desa Tonduk. Gambaran selengkapnya mengenai daerah penangkapan ikan menurut alat penangkapan ikan di wilayah studi dapat dilihat pada Gambar 4.

Hasil wawancara diketahui bahwa armada penangkapan pancing tonda menggunakan mesin penggerak dongfeng $24 \mathrm{PK}$. Waktu tempuh dari Desa Tonduk sekitar 2 jam dengan angka kecepatan sesuai dengan GPS yaitu sebesar 9 $\mathrm{km}$ per jam. Penentuan dari daerah penangkapan nelayan di Kecamatan Raas ini berdasarkan dari informasi antar nelayan sendiri. Menurut Wiyono (2013) menyebutkan bahwa penentuan daerah penangkapan dengan memanfaatkan informasi nelayan lain dan pengalaman membuat pengoperasian alat penangkapan ikan cenderung dilakukan pada daerah yang sama dan sangat terbatas pada kawasan tertentu. Kondisi ini memnyebabkan kompetisi antar alat tangkap sangat tinggi sehingga berpeluang untuk terjadinya konflik antar nelayan.

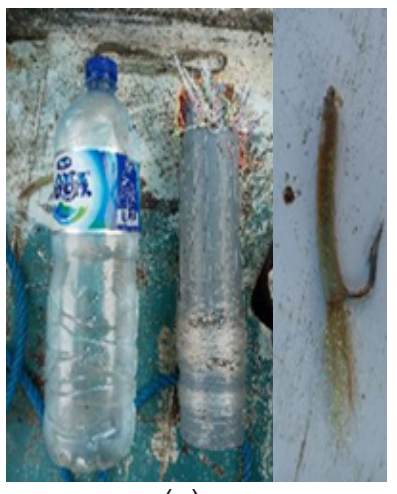

(a)

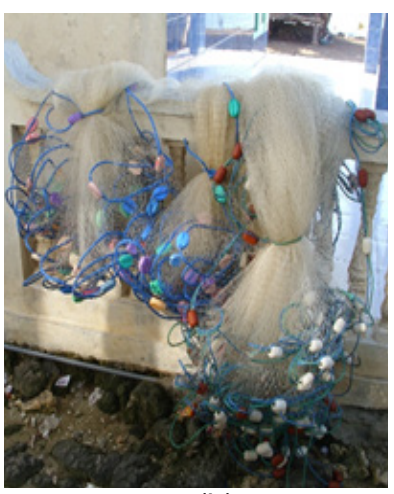

(b)

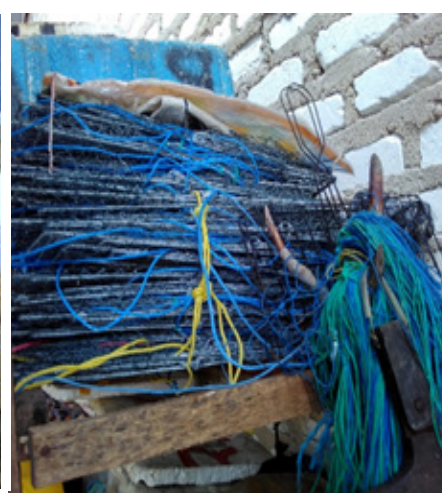

(c)

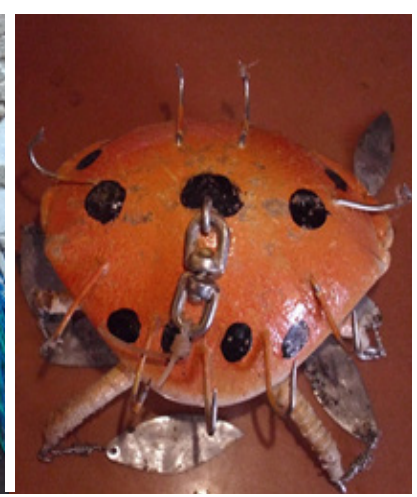

(d)

Gambar 3. Alat penangkap lkan di Lokasi Studi (a) Pancing Tonda (b) Gillnet (c) Bubu Lipat (d) Pancing Gurita. Figure 3. Fish Gears in the Study Site (a) Trolling Fishing Rod (b) Gillnet (c) Foldable Bubu (d) Octopus Fishing Rod. 

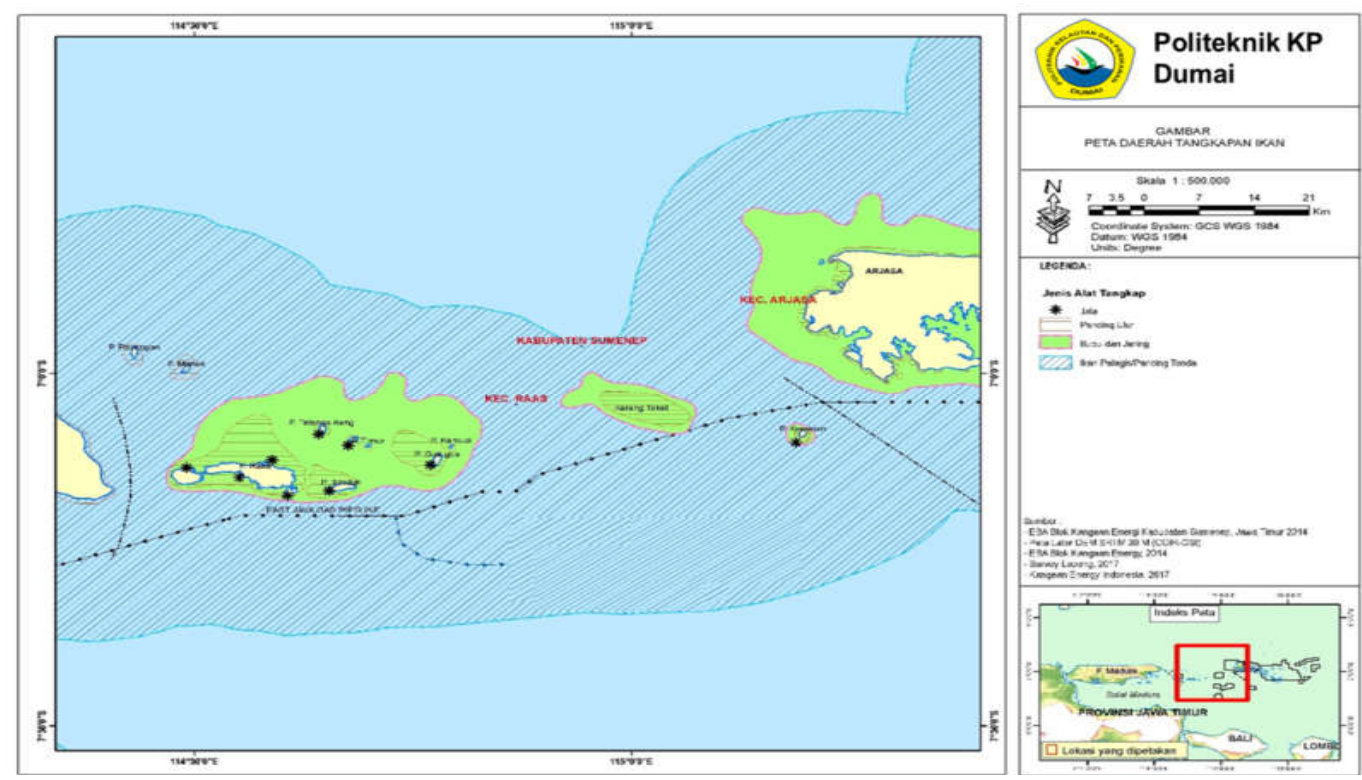

Gambar 4. Daerah Penangkapan di Lokasi Studi. Figure 4. Fishing Ground in the Study Site.

\section{E. Musim Penangkapan Ikan}

Musim penangkapan yang mempengaruhi operasi penangkapan ikan di Indonesia ada dua jenis yaitu musim barat yang terjadi pada bulan November-April dan musim timur yang terjadi pada bulan Mei-Oktober. Pada musim barat sering terjadi hujan dengan angin kencang disertai ombak besar sehingga banyak nelayan yang tidak melaut. Musim timur jarang terjadi hujan dan keadaan laut biasanya tenang. Musim timur inilah biasanya merupakan musim puncak banyak ikan. Untuk dapat melakukan operasi penangkapan dengan efisien diperlukan adanya informasi yang tepat seperti saat musim penangkapan yang baik. Informasi mengenai pola musim penangkapan digunakan untuk menentukan waktu yang tepat dalam pelaksanaan operasi penangkapan. Menurut Cochrane (2002), menjelaskan bahwa nelayan skala kecil sangat tergantung terhadap ekosistem laut yang dekat dengan tempat tinggal mereka yaitu daerah pantai, umumnya dilakukan dalam satu hari penangkapan dan menyesuaikan dengan pola musiman tertentu, dan sangat rentan dengan penurunan sumber daya ikan (McGoodwin, 2001).

Perbedaan penggunaan alat tangkap dan usaha penangkapan ikan sangat dipengaruhi oleh kondisi topografi pantai/pulau, angin, ombak, dan arus di daerah penangkapan. Kondisi perairan dengan angin dan gelombang besar biasanya terjadi mulai bulan Juli sampai Bulan September. Pada Musim Barat biasanya terjadi angin dan gelombang besar pada Bulan Januari sampai Bulan Februari. Pada waktu kecepatan angin tinggi yang menyebabkan laut gelombang laut besar akan menyulitkan nelayan untuk mengoperasikan alat tangkapnya, sehingga dapat dikatakan musim paceklik bagi nelayan. Tetapi, untuk nelayan yang menggunakan alat tangkap di dekat pantai bisa beroperasi dan hasil tangkapannya lebih banyak. Lebih rinci terkait pola musim tangkapan dan perkiraan hasil tangkapan nelayan Kecamatan Raas berdasarkan hasil wawancara tersaji pada Tabel 5.

Pola musim masing-masing spesies memiliki pola yang tidak selalu sama dengan pola musim ikan umumnya. Spesies ikan tuna, tongkol dan cakalang memiliki pola musim yang sama dengan pola musim ikan pada umumnya yaitu Mei-Oktober. Spesies ikan cucut, lobster dan bawal memiliki pola musim yang berlawanan dengan pola musim umumnya yaitu Januari-Maret dan NovemberDesember. Salas et al. (2004), menjelaskan bahwa nelayan tidak beroperasi secara acak tetapi mempertimbangkan informasi tentang ketersediaan sumber daya dan pendapatan yang dihasilkan dari penangkapan sebelumnya, sebelum memilih atau menetapkan target penangkapan.

Kesimpulan yang didapat dari hasil penelitian ini menyebutkan bahwa karakteristik perikanan tangkap yang ada di pulau-pulau kecil dengan studi kasus di Kepulauan Kangean khususnya di Kecamatan Raas adalah neleyan skala kecil. 
Tabel 5. Pola Musim Tangkapan Ikan Nelayan Kecamatan Raas Berdasarkan Alat Tangkap. Table 5. Catching Season Pattern of Fishing Fish in the of Raas Sub Regency Based on Fishing Gear.

\begin{tabular}{|c|c|c|}
\hline No & Target/ Target & Pola Musim Penangkapan Ikan/ Seasonal Pattern of Fishing \\
\hline 1 & Gillnet/Gillnet Gear & $\begin{array}{l}\text { - } \text { Musim Puncak : Bulan } 2 \text { - 5 / Season of Month } 2 \text { - } 5 \\
\text { - } \text { Musim Sedang : Bulan 10-12/ Season of Month } 10-12 \\
\text { - } \text { Musim Paceklik : Bulan 6-9/ Season of Month } 6-9\end{array}$ \\
\hline 2 & $\begin{array}{l}\text { Pancing Ulur/Hand } \\
\text { line Gear }\end{array}$ & $\begin{array}{l}\text { - Musim Puncak : Bulan 2-7/ Season of Month } 2-7 \\
\text { - Musim Sedang : Bulan 11-1/ Season of Month } 11-1 \\
\text { - Musim Paceklik : Bulan 6-10/Season of Month } 6-10\end{array}$ \\
\hline 3 & Pancing Tonda & $\begin{array}{l}\text { - Musim Puncak : Bulan } 10-11 \text { / Season of Month } 10-11 \\
\text { - Musim Sedang : Bulan } 3-6 \text { / Season of Month } 3-6 \\
\text { - } \text { Musim Paceklik : Bulan 12-2; 7-9 / Season of Month 12-2; 7-9 }\end{array}$ \\
\hline
\end{tabular}

Sumber : Hasil Wawancara/Source: Interview Result

Nelayan skala kecil yang ada di lokasi penelitian ini melakukan aktivitas penangkapan hanya berda disekitar pantai dan tidak jauh dari pantai. Beberapa alat tangkap yang digunakan oleh nelayan kecil di lokasi studi adalah pancing tonda, pancing gurita, gillnet, pancing ulur, dan bubu lipat. Armada penangkapan yang digunakan oleh nelayan kecil di lokasi studi sebagian besar adalah kapal tanpa motor (sampan) sebanyak 62\% dan kapal motor dengan kapasistas $<5$ GT sebanyak $30 \%$. Musim penangkapan dari nelayan kecil ini sangat dipengaruhi oleh musim dan kondisi ekosistem perairan disekitar.

\section{SINTESA KEBIJAKAN}

Aktivitas perikanan tangkap yang ada di pulau-pulau kecil mempunyai peran yang penting dalam perekonomian suatu wilayah. Aktivitasnya menjadi menjadi penopang utama perekonomian bagi para pelakunya (nelayan, pedagang, pengepul, pengecer, penyedia sarana dan prasarana, penyedia jasa angkutan, pengolahan dan lainlain). Kepulauan Kangean merupakan salah satu pulau-pulau kecil yang ada di Indonesia, dimana aktivitas perikanan tangkap menjadi sumber penghidupan bagi masyarakat dan nelayan yang ada disana. Kebijakan untuk mengembangkan aktivitas perikanan tangkap di pulau-pulau kecil masih sangat dibutuhkan dengan memperhatikan potensi sumber daya perikanan sebagai penggerak utama perekonomiannya. Perlu keterpaduan sumber daya dengan pelaku uasaha (nelayan, pedagang, penyedia sarana dan prasaran pengolah dan penyedi jasa) sehingga mampu menggerakkan perekonomian berbasis sumber daya perikanan.

Peningkatan manajemen usaha perikanan tangkap dalam rumah tangga sangat diperlukan bagi nelayan-nelayan yang ada di pulau kecil untuk dapat meningkatkan kesejahteraan dan aktivitas perekonomian nelayan yang ada di pulaupulau kecil. Sehingga, keterpaduan antara peran pemerintah, swasta, akademisi, masyarakat dan para stakeholder lain dibidang perikanan tangkap dapat meningkatkan aktivitas perikanan tangkap di pulau-pulau kecil. Potensi yang perlu ditingkatkan lagi yaitu sumber daya manusia dari peran wanita nelayan agar bisa membuat usaha skala rumah tangga sehingga dapat meningkatkan pendapatan

\section{IMPLIKASI KEBIJAKAN}

Berdasarkan hasil penelitian diatas, maka dapat disarankan dan diaplikasikan dalam konsep pengembangan kebijakan perikanan skala kecil yang harus memperhatikan kondisi potensi sumber daya perikanan, tingkat eksploitasi, tingkat kestabilan hasil tangkapan berdasarkan musim dan cuaca dalam mengembangkan kebijakan direktif yang fokus untuk nelayan skala kecil. Sehingga kedepannya kebijakan untuk pengembangan perikanan skala kecil lebih diperhatikan lagi khususnya untuk kestabilan hasil tangkapan dengan pengembangan alternatif penangkapan dan alat tangkap yang telah digunakan dengan pola kepemilikan alat tangkap ganda (multi gear). Implikasi kebijakan yang perlu di ambil yaitu perluasan sumbersumber ekonomi yang perlu dikembangkan untuk nelayan perikanan skala kecil. 


\section{UCAPAN TERIMA KASIH}

Pada kesempatan ini penulis mengucapkan terimakasih kepada semua pihak yang telah membantuu dalam penelitian, khususnya kepada Pusat Kajian Sumberdaya Pesisir dan Laut, LPPM-IPB (PKSPL-LPPM IPB) yang telah mendanai dan membantu dalam kelancaran penelitian. Selain itu penulis juga mengucapkan terima kasih kepada semua pihak yang terlibat di dalam penelitian ini sehingga penulis dapat menyelesaikan penelitian dengan lancar dan baik.

\section{PERNYATAAN KONTRIBUSI PENULIS}

Kontribusi penulis Suci Asrina Ikhsan menyusun dan menyempurnakan manuskrip sebagai kontributor utama dan penulis Muhammad Nur Arkham mengambil data dan menganalisis data sebagai kontributor anggota.

\section{DAFTAR PUSTAKA}

Arkham, M. N., Adrianto, L., \& Wardiatno, Y. (2015a). Konektivitas Sistem Sosial-Ekologi Lamun dan Perikanan Skala Kecil di Desa Malang Rapat dan Desa Berakit, Kabupaten Bintan, Kepulauan Riau. Jurnal IImu dan Teknologi Kelautan Tropis, 7(2), 433-452. doi : 10.29244/jitkt.v12i2.

Arkham, M. N., Adrianto, L., \& Wardiatno, Y. (2015b). Studi Keterkaitan Ekosistem Lamun dan Perikanan Skala Kecil ( Studi Kasus : Desa Malang Rapat dan Berakit , Kabupaten Bintan , Kepulauan Riau). J. Sosek KP, 10(2), 137-148. Retrieved from http://ejournal-balitbang.kkp.go.id/index. php/sosek/index.

Berkes, F., Mahon, R., McConney, P., Pollnac, R. \& Pomeroy, R. (2008). Mengelola Perikanan Skala Kecil Arah dan Metode Alternatif. International Development Researh Center. Kanada.

BPS Kabupaten Sumenep. (2019). Sumenep Dalam Angka 2019. Badan Pusat Statistik Kabupaten Sumenep.

Carles, Wiyono, E. S., Wisudo, S. H., \& Soeboer, D. A. (2014). Characteristics of capture fisheries in Simeulue Districts sea waters area. Marine Fisheries, 5(1), 91-99. Retrieved from http:// journal.ipb.ac.id/index.php/jpsp/index.

Cochrane, K. L. (2002). A fishery manager.s guidebook. Management measures and their application. FAO Fisheries Technical Paper. No. 424. Rome, FAO. 2002. 231p. Retrieved from https://books. google.co.id.

Creswell, J. W. (2010). Research Desaign: Pendekatan Kuantitatif, Kualitatif dan Mixed. Pustaka Pelajar. Indonesia.
Fathanah, Y. (2014). Analisis Karakteristik Perikanan Tangkap Skala Kecil di Kabupaten Pacitan, Jawa Timur. Tesis. IPB University. Retrieved from https://repository.ipb.ac.id/handle/123456789/9.

Imam, T. (2012). Potensi dan Peluang Pengembangan Usaha Perikanan Tangkap Di Pantura Jawa Tengah. Saintek Perikanan, 8(1), 65-73. doi: 10.14710/ijfst.8.1.65-73.

McConney \& Charles, A. T. (2008). Managing Small-Scale Fisheries: Moving Towards People-Centred Perspectives. Handbook of Marine Fisheries Conservation and Management. 1-2 hal. http:// husky1.stmarys.ca/ charles/ PDFS_2005/ 059. pdf

McGoodwin, J. R. (2001). Understanding the cultures of fishing communities. A Key to fisheries management and food security. FAO.

Nababan, B. O., Sari, Y. D., \& Maman, H. (2008). Tinjauan Aspek Ekonomi Keberlanjutan Perikanan Tangkap Skala Kecil Di Kabupaten Tegal Jawa Tengah. Buletin Ekonomi Perikanan. 8 (3), 21-32. Retrieved from https://journal.ipb.ac.id/index.php/ bulekokan.

Nurdiani, N. (2014). Teknik Sampling Snowball dalam Penelitian Lapangan. ComTech. 5(2), 1110-1118. Retrieved from https://journal.binus.ac.id/index. php/comtech.

Romdhon, A. (2014). Strategi Konservasi Pulau Kecil melalui Pengelolaan Perikanan Berkelanjutan (Studi Kasus Pulau Gili Labak, Sumenep). Jurnal Kelautan. 7(2), 86-93. Retrieved from https:// journal.trunojoyo.ac.id/jurnalkelautan.

Salas, S., Sumaila, U. R., dan Pitcher, T. (2004). Short-term decisions of small-scale fishers selecting alternative target species: a choice model. Canadian Journal Fisheries Aquatic Science 61, 374-383. Retrieved from https:// www.nrcresearchpress.com/loi/cjfas.

Sinabutar, P. (2015). Penataan Tenurial dan Peran Para Pihak dalam Mewujudkan Legalitas dan Legitimasi Kawasan Hutan Negara. Disertasi. Bogor (ID): Institut Pertanian Bogor. Retrieved from https://repository.ipb.ac.id/ handle/123456789/9.

Wiyono, E. S. (2013). Kendala dan Strategi Operasi Penangkapan Ikan Alat Tangkap Bubu di Muara Angke, Jakarta. Jurnal IImu Perikanan Tropis. 18(2): 14-20 [Internet]. [diunduh pada 2019 Oktober 23]. Retrieved from https://fpik.unmul. ac.id/wp-content/uploads/2013/07/3-EKO-KENDALA-STRATEGI -OPERASI.Pdf. 